\title{
Article \\ Combination of Static Echocardiographic Indices for the Prediction of Fluid Responsiveness in Patients Undergoing Coronary Surgery: A Pilot Study
}

\author{
Hye-Bin Kim (D), Sarah Soh, Jong-Wook Song, Min-Yu Kim (D), Young-Lan Kwak (D) and Jae-Kwang Shim *(D) \\ Department of Anesthesiology and Pain Medicine, Anesthesia and Pain Research Institute, Yonsei University \\ College of Medicine, Seoul 03722, Korea; kakddugi@yuhs.ac (H.-B.K.); yeonchoo@yuhs.ac (S.S.); \\ sjw72331@yuhs.ac (J.-W.S.); minyu92@yuhs.ac (M.-Y.K.); ylkwak@yuhs.ac (Y.-L.K.) \\ * Correspondence: aneshim@yuhs.ac; Tel.: +82-2-2228-8500; Fax: +82-2-364-2951
}

Citation: Kim, H.-B.; Soh, S.; Song, J.-W.; Kim, M.-Y.; Kwak, Y.-L.; Shim, J.-K. Combination of Static

Echocardiographic Indices for the Prediction of Fluid Responsiveness in Patients Undergoing Coronary Surgery: A Pilot Study. J. Clin. Med. 2021, 10, 1886. https://doi.org/ 10.3390/jcm10091886

Academic Editor: Fabrizio Monaco

Received: 26 January 2021

Accepted: 22 April 2021

Published: 27 April 2021

Publisher's Note: MDPI stays neutral with regard to jurisdictional claims in published maps and institutional affiliations.

Copyright: (c) 2021 by the authors. Licensee MDPI, Basel, Switzerland. This article is an open access article distributed under the terms and conditions of the Creative Commons Attribution (CC BY) license (https:// creativecommons.org/licenses/by/ $4.0 /)$.

\begin{abstract}
We investigated the role of echocardiographic indices consisting of left ventricular enddiastolic area (LVEDA) in combination with Doppler-derived surrogates of diastolic compliance and filling (E/E', $E^{\prime} / S^{\prime}, E^{\prime} / A^{\prime}$; early transmitral flow velocity (E), tissue Doppler-derived early $\left(E^{\prime}\right)$ diastolic, late $\left(\mathrm{A}^{\prime}\right)$ diastolic, or peak systolic $\left(\mathrm{S}^{\prime}\right)$ velocity of the mitral annulus) in predicting fluid responsiveness in off-pump coronary surgery. Hemodynamic and echocardiographic variables were prospectively assessed under general anesthesia before and after a fluid challenge of $6 \mathrm{~mL} / \mathrm{kg}$ during apnea at atmospheric pressure in 64 patients with LV ejection fraction $\geq 40 \%$. Forty patients (63\%) were fluid responders ( $\geq 15 \%$ increase in stroke volume index). $E / E^{\prime}$ and $E^{\prime} / S^{\prime}$ could predict fluid responsiveness with area under the receiver operating characteristic curve (AUROC) of 0.71 (95\% confidence interval [CI], 0.56-0.85; $p=0.006)$ and 0.68 (95\% CI, 0.54-0.82; $p=0.017)$, respectively. The combination of LVEDA and $\mathrm{E} / \mathrm{E}^{\prime}$ showed incremental predictive ability for fluid responsiveness compared with LVEDA (AUROC, $0.60 ; p=0.170$ ) or pulse pressure variation (AUROC, 0.70; $p=0.002)$, yielding the highest AUROC of 0.78 (95\% CI, 0.66-0.90; $p<0.001)$. The combined index of echocardiographic variables reflecting LV dimension (LVEDA) and diastolic compliance and filling $\left(E / E^{\prime}\right)$ is a potentially useful predictor of fluid responsiveness.
\end{abstract}

Keywords: left ventricular end-diastolic area; stroke volume index; Frank-Starling mechanism; cardiac preload; fluid responsiveness; echocardiography; doppler

\section{Introduction}

For perioperative and critical care, appropriate fluid resuscitation guided by reliable preload indices is of pivotal importance as only half of the patients are fluid responsive [1] and superfluous fluid administration actually leads to increased mortality [2]. So far, emerging evidence advocates the ability of dynamic preload indices, such as pulse pressure variation (PPV) or stroke volume variation, to determine a patient's status on the FrankStarling curve and thus, fluid responsiveness [3]. However, these dynamic indices are subject to limitations related to heart-lung interaction and arrhythmia [4], which may preclude their use in patients receiving lung-protective ventilation or those with a rhythm other than sinus, spontaneous breathing efforts, pulse pressure hypertension or pulmonary hypertension $[5,6]$.

By contrast, the assessment of static preload indices is feasible regardless of heart rhythm or heart-lung interaction, while they are unable to predict fluid responsiveness. Indeed, the use of invasively acquired measures of filling pressures using a pulmonary artery catheter (PAC) for assessing fluid responsiveness has been discouraged [7]. Similarly, the predictive ability of a static echocardiographic index, left ventricular end-diastolic area (LVEDA), for fluid responsiveness is also poor [3]. On the other hand, echocardiographic measurements of combinations of early transmitral flow velocity (E), tissue Doppler- 
derived early $\left(\mathrm{E}^{\prime}\right)$ diastolic, late $\left(\mathrm{A}^{\prime}\right)$ diastolic, or peak systolic $\left(\mathrm{S}^{\prime}\right)$ velocity of the mitral annulus may provide surrogate information regarding $L V$ filling pressure $\left(E / E^{\prime}\right)$, preload $\left(E^{\prime} / S^{\prime}\right)$ and stiffness $\left(E^{\prime} / A^{\prime}\right)[8-11]$.

Hypothetically, combining LVEDA and these indices would provide more insights regarding the LV dimension, as well as diastology (compliance and filling) that governs the ventricular response to a fluid challenge [11], which could be used to identify fluid responders. Moreover, these values can be reliably obtained non-invasively regardless of respiratory status or heart rhythm (except for $\mathrm{A}^{\prime}$ ). The primary aim of this prospective trial was to investigate the role of echocardiographic indices, including LVEDA, combined with Doppler-derived parameters of diastolic compliance and filling in predicting fluid responsiveness in patients undergoing surgical coronary revascularization.

\section{Materials and Methods}

\subsection{Participants}

The current study was conducted at Severance Cardiovascular Hospital, Yonsei University Health System, Seoul, Republic of Korea, after being approved by the institutional review board (IRB number: 4-2017-0403) and registered at the clinicaltrials.gov (NCT03222778) before recruitment started. This study was conducted following the Strengthening the Reporting of Observational Studies in Epidemiology (STROBE) guidelines and according to the Declaration of Helsinki. A total of 66 patients scheduled for off-pump coronary surgery between August 2017 and March 2020 were enrolled after obtaining written informed consent. The exclusion criteria were kidney disease requiring renal replacement therapy, heart rhythm other than sinus, LV ejection fraction $<40 \%$, lateral wall motion abnormalities, or any valvular heart disease of $\geq$ moderate severity.

\subsection{Anesthetic Management}

All subjects received standardized anesthetic care as previously described [12]. In brief, anesthesia was maintained with the continuous infusion of sufentanil and sevoflurane and neuromuscular blockade using rocuronium. The ventilator was set to deliver $8 \mathrm{~mL} / \mathrm{kg}$ (ideal body weight) of oxygen at a respiratory rate of $8-14$ breaths/min, I:E ratio of 1:2 and a positive end-expiratory pressure of $5 \mathrm{cmH}_{2} \mathrm{O}$. The inspired oxygen fraction was 0.4 with air. A PAC and transesophageal echocardiography (TEE) probe were inserted in all patients and the former was connected to a Vigilance II monitor (Edwards Lifesciences LLC, Irvine, CA, USA) assessing continuous cardiac output. PPV was acquired from the radial arterial pressure waveform connected to Philips Intellivue MP70 (Philips Medical Systems, Suresnes, France). The target mean arterial pressure during surgery was $60-80 \mathrm{mmHg}$, which was maintained by administering norepinephrine, vasopressin (added when the norepinephrine requirement exceeded $0.3 \mu \mathrm{g} / \mathrm{kg} / \mathrm{min}$ ), or nicardipine as necessary.

\subsection{Study Protocol}

Assessment of hemodynamic and echocardiographic variables was performed $15 \mathrm{~min}$ after the insertion of a PAC under general anesthesia (baseline) and $10 \mathrm{~min}$ after the completion of fluid challenge. A fluid challenge of $6 \mathrm{~mL} / \mathrm{kg}$ (ideal body weight) was performed for 10 min using 6\% balanced hydroxyethyl starch 130/0.4 (Volulyte ${ }^{\circledR}$; Fresenius Kabi, Bad Homburg, Germany).

Hemodynamic variables included mean arterial pressure, heart rate, PPV, central venous pressure (CVP), pulmonary artery occlusion pressure (PAOP), cardiac index and stroke volume index (SVI). PPV was obtained as an average of 4 cycles of $8 \mathrm{~s}$. Filling pressures were measured during apnea at atmospheric pressure. For cardiac index and SVI, the average of 3 serial STAT mode measurements was recorded.

Echocardiographic variables included LVEDA, E, E', $\mathrm{A}^{\prime}$ and $\mathrm{S}^{\prime}$. They were all measured with TEE during apnea at atmospheric pressure by a single examiner (J-K Shim). LVEDA measurements were obtained from the transgastric mid-papillary short axis view and $\mathrm{E}, \mathrm{E}^{\prime}, \mathrm{A}^{\prime}$ and $\mathrm{S}^{\prime}$ measurements were obtained from the midesophageal 4-chamber view. 
An average of 3-5 beats was recorded for LVEDA (papillary muscle excluded in tracing the leading edge of the endocardium; automatically computed by Siemens speckle-tracking algorithm (ACUSON SC2000 PrimeTM, eSie VVITM, Siemens Medical Solutions USA Inc., Mountain View, CA, USA)), E, $\mathrm{E}^{\prime}, \mathrm{A}^{\prime}$ and $\mathrm{S}^{\prime}$. Pulsed-wave Doppler measurement of E velocity was performed between the mitral leaflet tips. Tissue Doppler imaging (TDI) measurements of the $\mathrm{E}^{\prime}, \mathrm{A}^{\prime}$ and $\mathrm{S}^{\prime}$ were carried out at the lateral mitral annulus (sample volume, 2-3 mm; sweep speed, 50-100 mm/s). LVEDA and E, $E^{\prime}, A^{\prime}$ and $S^{\prime}$ values were all measured thrice each and the average value was used for analysis. Surgical incision was deferred until the completion of the last measurement. Measurements of the echocardiographic variables were conducted by J-K Shim who was blinded to the data on hemodynamic variables. Vasopressor requirement and plateau inspiratory pressure at the time of measurement were also recorded.

\subsection{Study Endpoints}

The primary endpoint was to assess the predictive abilities of the combined echocardiographic preload indices consisting of LVEDA and Doppler-derived parameters of diastolic compliance and filling $\left(E / E^{\prime}, E^{\prime} / S^{\prime}\right.$, or $\left.E^{\prime} / A^{\prime}\right)$ for fluid responsiveness (defined as a $\geq 15 \%$ increase in SVI). The secondary endpoint was to assess the predictive abilities of PPV, CVP, PAOP and LVEDA on fluid responsiveness and compare the predictive abilities of the combined echocardiographic preload indices with those of LVEDA or PPV alone.

\subsection{Statistical Analysis}

Statistical analyses were conducted using SAS (version 9.4; SAS Inc., Cary, NC, USA) and SPSS for Windows (Version 25; SPSS Inc., Chicago, IL, USA). Sample size was predicted under the assumption that the area under the receiver operating characteristic curve (AUROC) of the combined echocardiographic index would be greater by 0.2 than the previously reported AUROC of 0.64 of LVEDA alone [3], to aim for an AUROC of greater than 0.8 , which is usually considered as having a good predictive ability. Thus, 60 patients were required to obtain $80 \%$ power (alpha 0.05 ) assuming a fluid responsiveness rate of $60 \%$ [12] and a total of 66 patients were enrolled accounting for an additional drop-out rate of $10 \%$.

Intra-observer variabilities of the measured echocardiographic variables were assessed using the intra-class correlation coefficient by a one-way random effects model. An intraclass coefficient of more than 0.85 usually indicates that the measurement is consistent.

Continuous variables were first assessed for their normality using the KolmogorovSmirnov test. Intergroup comparisons of continuous variables between fluid responders and non-responders were performed using the independent $t$-test or Mann-Whitney $U$ test according to the results of the normality test. Intergroup comparisons of categorical variables between fluid responders and non-responders were conducted using the chisquare test or Fisher's exact test. Intragroup comparisons of continuous variables at baseline and after fluid challenge in both responders and non-responders were carried out using the paired $t$-test or the Wilcoxon signed-rank test according to the results of the normality test.

The AUROC was calculated for the potential candidates of preload indices to test their predictive ability for fluid responsiveness. To investigate the incremental value of combining echocardiographic indices for predicting fluid responsiveness, we performed multivariable logistic regression analysis and the AUROCs of the tested variables were compared using the DeLong test. A nomogram was constructed using a combination of echocardiographic indices showing the highest AUROC in the multivariable analysis.

Data are presented as mean \pm standard deviation (SD), median (25-75\% interquartile range (IQR)), or $n(\%)$. A value of $p<0.05$ was considered statistically significant. 


\section{Results}

The PAC could not be properly positioned in two patients who were then excluded from the data analysis; thus, data from only 64 patients were analyzed. A total of 40 patients $(63 \%)$ were fluid responders. The intra-class coefficients of echocardiographic variables that were measured thrice and averaged were $0.96,0.98,0.96,0.94$ and 0.96 for LVEDA, E, $\mathrm{E}^{\prime}, \mathrm{S}^{\prime}$ and $\mathrm{A}^{\prime}$, respectively, indicating excellent reproducibility. Intergroup comparisons of patients' characteristics between responders and non-responders are displayed in Table 1. None of the patients required norepinephrine infusion in excess of $0.3 \mu \mathrm{g} / \mathrm{kg} / \mathrm{min}$ (median dose requirement $0.04 \mu \mathrm{g} / \mathrm{kg} / \mathrm{min}$ ).

Table 1. Patients' characteristics.

\begin{tabular}{|c|c|c|c|}
\hline & $\begin{array}{l}\text { Responders } \\
\quad(n=40)\end{array}$ & $\begin{array}{l}\text { Non-Responders } \\
\quad(n=24)\end{array}$ & $p$ \\
\hline Age (years) & $66 \pm 8$ & $65 \pm 8$ & 0.577 \\
\hline Female & $12(30)$ & $2(8)$ & 0.042 \\
\hline Body mass index $\left(\mathrm{kg} / \mathrm{m}^{2}\right)$ & $25.3 \pm 2.6$ & $23.8 \pm 3.1$ & 0.037 \\
\hline Hypertension & $24(60)$ & $17(71)$ & 0.382 \\
\hline Diabetes mellitus & $12(30)$ & $15(63)$ & 0.011 \\
\hline Cerebrovascular accident & $7(18)$ & $0(0)$ & 0.039 \\
\hline Myocardial infarction (<3 months) & $4(10)$ & $2(8)$ & 1.000 \\
\hline Left main disease ( $>50 \%$ stenosis) & $17(43)$ & $10(42)$ & 0.948 \\
\hline $\operatorname{LVEF}(\%)$ & $64 \pm 6$ & $67 \pm 8$ & 0.227 \\
\hline \multicolumn{4}{|l|}{ Medications } \\
\hline Statin & $27(68)$ & $19(80)$ & 0.315 \\
\hline Nitrate & $16(40)$ & $10(42)$ & 0.895 \\
\hline Beta blocker & $19(48)$ & $14(58)$ & 0.401 \\
\hline Calcium channel blocker & $20(50)$ & $6(25)$ & 0.049 \\
\hline Renin-angiotensin system antagonist & $23(58)$ & $12(50)$ & 0.560 \\
\hline Patients requiring norepinephrine & $35(88)$ & $21(88)$ & 1.000 \\
\hline Plateau inspiratory pressure $\left(\mathrm{cmH}_{2} \mathrm{O}\right)$ & $15(14-16)$ & $15(14-16)$ & 0.486 \\
\hline
\end{tabular}

Note: Data are expressed as $n(\%)$, mean \pm standard deviation or median (interquartile range). Abbreviation: $\mathrm{LVEF}$, left ventricular ejection fraction.

Intergroup comparisons of hemodynamic variables and invasive indices of preload between responders and non-responders are displayed in Table 2. At baseline, no significant intergroup differences were found in the assessed variables including CVP and PAOP, except SVI and PPV, which were significantly lower and higher, respectively, in the responder group than in the non-responder group. After the fluid challenge, all variables showed significant changes from their corresponding baseline values, except cardiac index and SVI in the non-responder group.

Table 2. Hemodynamic variables and invasive preload indices at baseline and after fluid challenge.

\begin{tabular}{|c|c|c|c|c|c|c|}
\hline & \multicolumn{3}{|c|}{ Responders $(n=40)$} & \multicolumn{3}{|c|}{ Non-Responders $(n=24)$} \\
\hline & Baseline & After Fluid Challenge & $p$ & Baseline & After Fluid Challenge & $p$ \\
\hline HR (bpm) & $59 \pm 9$ & $55 \pm 6$ & $<0.001$ & $57 \pm 5$ & $55 \pm 5$ & $<0.001$ \\
\hline MAP (mmHg) & $72 \pm 8$ & $76 \pm 9$ & $<0.001$ & $70 \pm 8$ & $76 \pm 6$ & $<0.001$ \\
\hline MPAP (mmHg) & $17(15-19)$ & $20(18-22)$ & $<0.001$ & $16(14-17)$ & $19(17-22)$ & $<0.001$ \\
\hline $\mathrm{CI}\left(\mathrm{L} / \mathrm{min} / \mathrm{m}^{2}\right)$ & $2.1(1.9-2.3)$ & $2.6(2.3-2.9) *$ & $<0.001$ & $2.3(2.0-2.6)$ & $2.1(1.9-2.4)$ & $<0.001$ \\
\hline $\mathrm{SVI}\left(\mathrm{mL} /\right.$ beat $\left./ \mathrm{m}^{2}\right)$ & $35(32-38) *$ & $46(42-52) *$ & $<0.001$ & $38(33-48)$ & $37(34-44)$ & $<0.001$ \\
\hline $\mathrm{CVP}(\mathrm{mmHg})$ & $9(8-11)$ & $12(10-13)$ & $<0.001$ & $9(8-10)$ & $11(10-13)$ & $<0.001$ \\
\hline PAOP (mmHg) & $13(12-14)$ & $16(14-17)$ & $<0.001$ & $12(10-14)$ & $15(13-18)$ & $<0.001$ \\
\hline PPV (\%) & $13(8-14)^{*}$ & $4(3-6) *$ & $<0.001$ & $9(7-11)$ & $6(5-7)$ & $<0.001$ \\
\hline
\end{tabular}

Note: Data are expressed as mean \pm standard deviation or median (interquartile range). ${ }^{*}$ Statistical significance between responders and non-responders. HR, heart rate; MAP, mean arterial pressure; MPAP, mean pulmonary arterial pressure; CI, cardiac index; SVI, stroke volume index; $\mathrm{CVP}$, central venous pressure; PAOP, pulmonary artery occlusion pressure; PPV, pulse pressure variation. 
Intergroup comparisons of echocardiographic indices of preload between responders and non-responders are displayed in Table 3. At baseline, no significant intergroup differences were observed in the assessed variables including LVEDA, except $\mathrm{E} / \mathrm{E}^{\prime}$ and $\mathrm{E}^{\prime} / \mathrm{S}^{\prime}$, which were lower and higher, respectively, in the responder group than in the non-responder group. After the fluid challenge, all variables showed significant changes from their corresponding baseline values, except $\mathrm{E}^{\prime} / \mathrm{A}^{\prime}$ in the non-responder group.

Table 3. Echocardiographic preload indices at baseline and after fluid challenge.

\begin{tabular}{ccccc}
\hline & & Baseline & After Fluid Challenge & $p \mathbf{1}^{\text {a }}$ \\
\hline \multirow{2}{*}{ LVEDA } & Responder & $21.1 \pm 3.8$ & $23.9 \pm 3.6$ & $<0.001$ \\
$\left(\mathrm{~cm}^{2}\right)$ & Non-responder & $22.5 \pm 3.0$ & $23.9 \pm 2.7$ & $<0.001$ \\
& $p 2^{\mathrm{b}}$ & 0.140 & 0.990 & \\
\hline & Responder & $6.2(5.6-7.0)$ & $7.1(6.1-8.0)$ & $<0.001$ \\
$\mathrm{E} / \mathrm{E}^{\prime}$ & Non-responder & $8.2(6.1-9.2)$ & $8.9(7.4-9.8)$ & 0.031 \\
& $p 2$ & 0.006 & 0.002 & 0.004 \\
$\mathrm{E}^{\prime} / \mathrm{S}^{\prime}$ & Responder & $0.9 \pm 0.2$ & $1.0 \pm 0.2$ & 0.035 \\
& Non-responder & $0.8 \pm 0.2$ & $0.9 \pm 0.2$ & 0.013 \\
& $p 2$ & 0.024 & 0.099 & 0.147 \\
$\mathrm{E}^{\prime} / \mathrm{A}^{\prime}$ & Responder & $1.3(1.0-1.5)$ & $1.4(1.2-1.6)$ & \\
& Non-responder & $1.1(0.9-1.4)$ & $1.1(0.9-1.5)$ & 0.048 \\
\hline
\end{tabular}

Note: Data are expressed as mean \pm standard deviation or median (interquartile range). ${ }^{\text {a }}$ Statistical significance between baseline and after volume expansion. ${ }^{b}$ Statistical significance between responders and non-responders. Abbreviations: LVEDA, left ventricular end-diastolic area; E, early transmitral flow velocity; E', early-diastolic velocity of the lateral mitral annulus; $\mathrm{S}^{\prime}$, peak systolic velocity of the lateral mitral annulus; $\mathrm{A}^{\prime}$, late-diastolic velocity of the lateral mitral annulus.

The results of ROC curve analysis of the potential candidates of preload indices are displayed in Table 4. Among the invasive indices of preload, only PPV was able to predict fluid responsiveness with an AUROC of 0.70 (95\% CI, $0.57-0.83$; $p=0.002)$. Among the echocardiographic indices of preload, $E / E^{\prime}$ and $E^{\prime} / \mathrm{S}^{\prime}$ could predict fluid responsiveness with AUROCs of $0.71(95 \%$ CI, $0.56-0.85 ; p=0.006)$ and 0.68 (95\% CI, $0.54-0.82 ; p=0.017)$, respectively. The combination of LVEDA and $\mathrm{E} / \mathrm{E}^{\prime}$ in the multivariable model showed incremental predictive ability for fluid responsiveness compared with LVEDA or PPV alone (Table 4 and Figure 1), yielding the highest AUROC of 0.78 (95\% CI, $0.66-0.90 ; p<0.001$ ). Power calculation from the observed results yielded a power of $87 \%$. The AUROC of the combination of LVEDA and E/E' was significantly larger than that of the LVEDA alone $(p=0.020)$ while the AUROC of the PPV was not when compared to that of the LVEDA $(p=0.326)$.

Accordingly, a nomogram was constructed with LVEDA and E/ $\mathrm{E}^{\prime}$ using a logistic regression model, which showed the highest AUROC (Figure 2A). The $p$ value of the Hosmer-Lemeshow goodness-of-fit test was 0.384 , indicating the adequacy of the constructed nomogram. The mean absolute error of the calibration plot of the nomogram was 0.021 . This result indicates good correlation between the predicted probability proposed by the nomogram and the actual probability of fluid responsiveness (Figure 2B). 
Table 4. Receiver operating characteristic curves of indices of predicting fluid responsiveness.

\begin{tabular}{|c|c|c|c|}
\hline & AUROC & $95 \% \mathrm{CI}$ & $p$ \\
\hline \multicolumn{4}{|l|}{ Invasive indices } \\
\hline Central venous pressure & 0.58 & $0.43-0.73$ & 0.311 \\
\hline Pulmonary artery occlusion pressure & 0.56 & $0.41-0.71$ & 0.442 \\
\hline Pulse pressure variation & 0.70 & $0.57-0.83$ & 0.002 \\
\hline \multicolumn{4}{|l|}{ Echocardiographic indices } \\
\hline Left ventricular end-diastolic area & 0.60 & $0.46-0.74$ & 0.170 \\
\hline $\mathrm{E} / \mathrm{E}^{\prime}$ & 0.71 & $0.56-0.85$ & 0.006 \\
\hline$E^{\prime} / S^{\prime}$ & 0.68 & $0.54-0.82$ & 0.017 \\
\hline $\mathrm{E}^{\prime} / \mathrm{A}^{\prime}$ & 0.61 & $0.47-0.75$ & 0.140 \\
\hline \multicolumn{4}{|l|}{ Combination of echocardiographic indices } \\
\hline Left ventricular end-diastolic area with $\mathrm{E} / \mathrm{E}^{\prime}$ & 0.78 & $0.66-0.90$ & $<0.001$ \\
\hline Left ventricular end-diastolic area with $E^{\prime} / S^{\prime}$ & 0.68 & $0.54-0.82$ & 0.012 \\
\hline Left ventricular end-diastolic area with $\mathrm{E}^{\prime} / \mathrm{A}^{\prime}$ & 0.66 & $0.52-0.80$ & 0.026 \\
\hline
\end{tabular}

Abbreviations: AUROC, area under the receiver operating characteristic curve; $\mathrm{CI}$, confidence interval; E, early transmitral flow velocity; $E^{\prime}$, early-diastolic velocity of the lateral mitral annulus; $S^{\prime}$, peak systolic velocity of the lateral mitral annulus; $\mathrm{A}^{\prime}$, late-diastolic velocity of the lateral mitral annulus.

\section{ROC Curves for Comparisons}

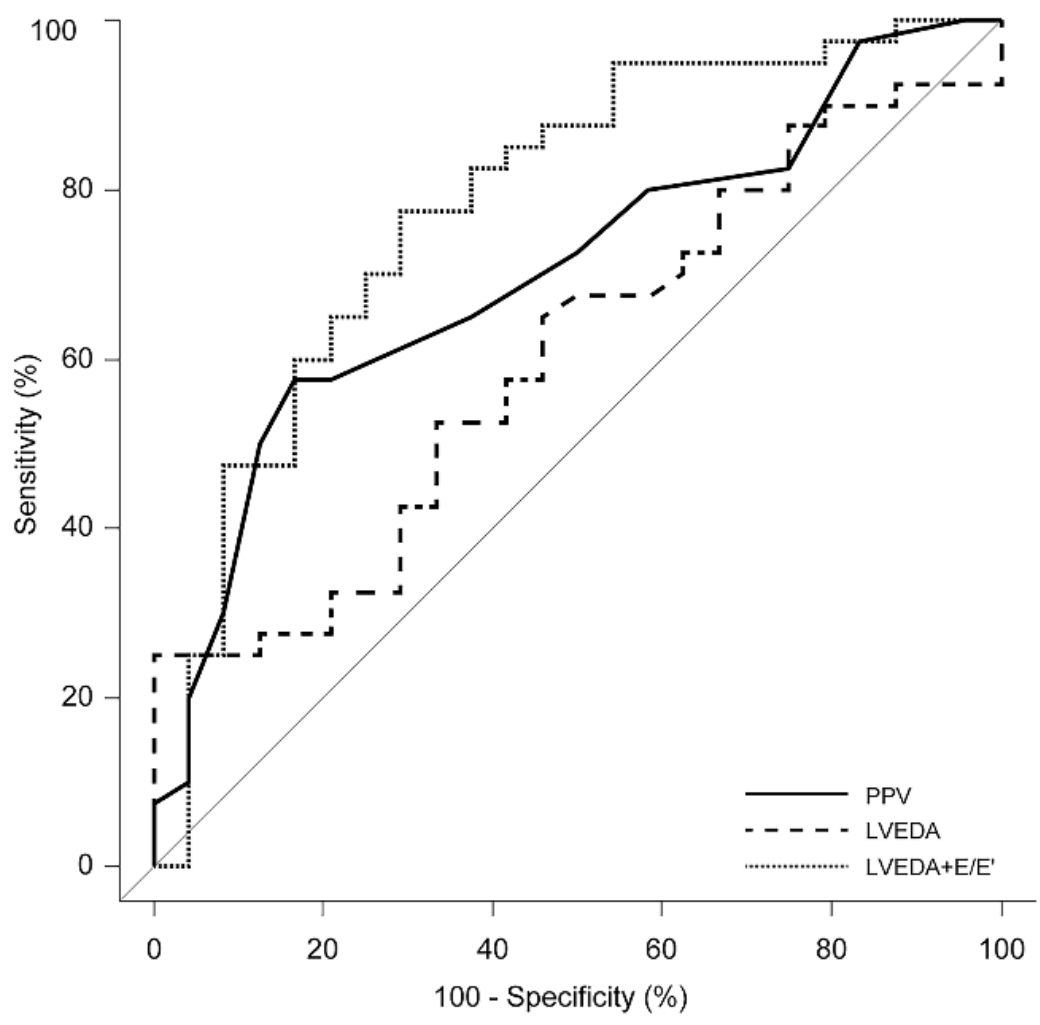

Figure 1. Comparison of receiver operating characteristic (ROC) curves of pulse pressure variation (PPV; solid line; AUROC, 0.70; 95\% CI, 0.57-0.83; $p=0.002$ ), left ventricular end-diastolic area (LVEDA; dashed line; AUROC, $0.60 ; 95 \%$ CI, $0.46-0.74 ; p=0.170$ ) and combination of LVEDA and the ratio of early transmitral flow velocity to early diastolic velocity of the mitral annulus (LVEDA + E/E'; dotted line; AUROC, $0.78 ; 95 \%$ CI, 0.66-0.90; $p<0.001)$. Abbreviations: AUROC, area under the ROC curve; CI, confidence interval. 
A

Points $\begin{array}{lllllllllll}0 & 10 & 20 & 30 & 40 & 50 & 60 & 70 & 80 & 90 & 100\end{array}$

LVEDA $\begin{array}{rrrrrr}30 & 26 & 22 & 18 & 14 & 10\end{array}$

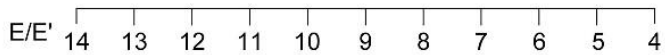

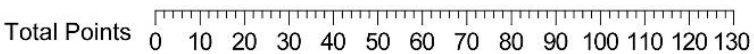

\begin{tabular}{llllllllllllll|ll} 
Probability & 0.05 & 0.1 & 0.2 & 0.3 & 0.4 & 0.5 & 0.6 & 0.7 & 0.8 & 0.9
\end{tabular}

B

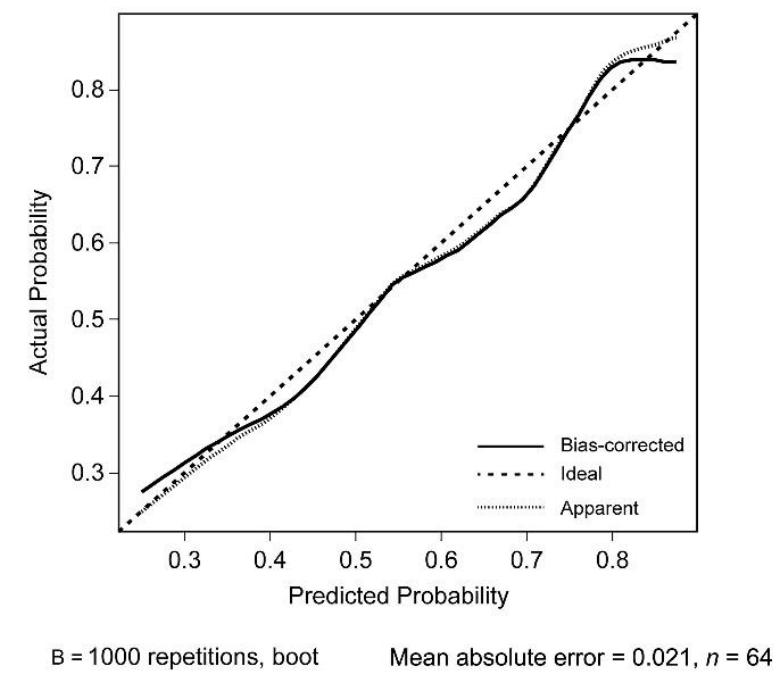

Figure 2. (A) Nomogram constructed with combination of left ventricular end-diastolic area (LVEDA) and the ratio of early mitral flow velocity to early diastolic velocity of the mitral annulus (E/E'). The $p$ value of the Hosmer-Lemeshow goodness-of-fit test was 0.384 . (B) Calibration plot comparing the actual and predicted probability of fluid responsiveness proposed by the nomogram with a mean absolute error of $0.021, n=64$.

\section{Discussion}

In the current pilot study, we validated that the combination of static echocardiographic variables, LVEDA with $\mathrm{E} / \mathrm{E}^{\prime}$, can predict fluid responsiveness; this combination showed the highest predictive ability among the concomitantly assessed preload indices, including $\mathrm{PPV}$, in patients with preserved LV ejection fraction requiring surgical coronary revascularization.

In recent years, point-of-care ultrasound has become an important pillar of critical care as it can not only provide straightforward answers regarding some of the underlying causes of the hemodynamic instability but also guide fluid therapy [13]. In that context, echocardiographic dynamic indices, such as peak flow, velocity-time integral of the ascending aorta or carotid artery and diameter of the inferior or superior vena cava, have also emerged as useful predictors of fluid responsiveness [12,14]. However, these indices are also subject to the same inherent limitations related to heart-lung interaction [15]. By contrast, static preload indices, such as invasive filling pressures and non-invasive echocardiographic variables, can be readily and reliably assessed at end-expiration atmospheric pressure, regardless of the ventilatory status or heart rhythm of the patients. However, their 
predictive abilities for fluid responsiveness are absent as these indices lack information with regard to ventricular compliance and filling [7], which would exert significant influence on the ventricular response to a fluid challenge for the following reasons. The extent to which myocytes are stretched by a given preload is governed by muscle compliance [16]. Thus, the Frank-Starling mechanism and preload dependence would be significantly altered when myocyte extension is inadequate due to impaired relaxation or reduced distensibility [11].

For the investigation of diastolic function, TDI has become an invaluable tool and has been incorporated in the recommendations proposed by responsible societies in that regard $[17,18]$. TDI-derived $E^{\prime}$ velocity tracks LV relaxation along the long axis and correlates well with the isovolumic LV relaxation rate [8]. As the major determinants of $\mathrm{E}$ velocity are left atrial pressure and $\mathrm{LV}$ relaxation rate, $\mathrm{E} / \mathrm{E}^{\prime}$ corrected for $\mathrm{LV}$ relaxation was shown to estimate LV filling pressure in cardiac patients with preserved and reduced LV function $[19,20]$. Although less specific, $E^{\prime} / \mathrm{A}^{\prime}$ has been proposed to reflect ventricular stiffness because stiffness is most pronounced in late diastole, in which $\mathrm{A}^{\prime}$ is reduced while $\mathrm{E}^{\prime}$ is less affected [9]. Moreover, $\mathrm{E}^{\prime} / \mathrm{S}^{\prime}$ has been proposed to reflect increased preload or systolic dysfunction considering the interdependence of these two variables and the compensatory increase in preload in case of low $S^{\prime}[10,21]$. In terms of assessing LV diastolic function, these Doppler-derived parameters fail to classify diastolic function in a fairly large number of patients as they may change acutely with altered loading conditions [22]. In contrast, these shortcomings of the Doppler-derived variables would theoretically be of great advantage in assessing fluid responsiveness as they would provide an instantaneous snapshot of LV diastolic mechanics at the time of assessment. Thus, we hypothesized that the combination of LVEDA and these parameters would act as a valuable preload index for predicting fluid responsiveness.

In the current study, only $E / E^{\prime}$ and $E^{\prime} / S^{\prime}$ could discriminate fluid responders albeit with low predictive powers (AUROC of 0.71 and 0.68 for $E / E^{\prime}$ and $E^{\prime} / S^{\prime}$, respectively), which are considered as poor for clinical use, while $E^{\prime} / \mathrm{A}^{\prime}$ or LVEDA could not. Among the invasive preload indices, only PPV was able to predict fluid responsiveness, but at a lower predictive power (AUROC of 0.70) as well, whereas CVP and PAOP could not. Of the combinations, LVEDA and $E / E^{\prime}$ yielded the highest predictive power (AUROC of 0.78 ), whereas the combinations of LVEDA and $\mathrm{E}^{\prime} / \mathrm{S}^{\prime}$ or $\mathrm{E}^{\prime} / \mathrm{A}^{\prime}$ could poorly predict fluid responsiveness (all AUROCs < 0.70), which may be attributable to the following. Global diastolic filling is mainly related to both early relaxation (active) and late elastic properties (passive) [23]. Although $\mathrm{E}$ and $\mathrm{E}^{\prime}$ all measure early diastolic events, $\mathrm{E}^{\prime}$ has also been validated to be related to elastic recoil, which governs passive relaxation $[23,24]$, implicating that $\mathrm{E}^{\prime}$ may comprehensively reflect diastolic filling. As E velocity is highly dependent on loading conditions, mainly determined by the left atrial pressure and LV relaxation, $\mathrm{E} / \mathrm{E}^{\prime}$ would yield sophisticated information related to the instantaneous LV compliance that may have imposed the incremental value for predicting fluid responsiveness when combined with LVEDA. A previous study outlined the ability of $\mathrm{E} / \mathrm{E}^{\prime}$ alone, in the context of reflecting LV compliance, to predict fluid responsiveness in patients requiring surgical coronary revascularization, with an AUROC of 0.74 , but its incremental value when combined with other parameters was not evaluated [25]. As indicated in the nomogram (Figure 2A), even an extremely low $\mathrm{E} / \mathrm{E}^{\prime}$ value of 4 alone can only yield a total point of 100 corresponding to a $70 \%$ probability of being fluid responsive, while the addition of information obtained from LVEDA assessment can increase the probability to over $90 \%$ (the lower the values of LVEDA and $E / E^{\prime}$, the more likely to be fluid responsive). By contrast, $E^{\prime} / A^{\prime}$ or $E^{\prime} / S^{\prime}$ is less specific and influenced by other factors, rendering their relationship with LV compliance less straightforward $[9,10,21]$.

PPV is one of the most useful dynamic preload indices assuming that all of the conditions for proper heart-lung interaction are met [3]. However, in the current study, PPV's predictive ability for fluid responsiveness was poor (AUROC of 0.70 ). Congruent to this result, previous studies have depicted that high preoperative $E / E^{\prime}(>15)$ and pulse pressure hypertension (>60 $\mathrm{mmHg}$ ), which are both closely related to diastolic dysfunction, 
resulted in abolished predictive ability of PPV or stroke volume variation in a similar subset of patients that require surgical coronary revascularization $[6,26]$. In the current study, $11(17 \%)$ and $9(14 \%)$ patients had high preoperative $E / E^{\prime}$ and pulse pressure hypertension, respectively, which may have attributed to the low predictive ability of PPV.

In theory, this combined static index of LVEDA and $\mathrm{E} / \mathrm{E}^{\prime}$ can potentially be applied to guide fluid therapy in clinical situations not suitable for the evaluation of dynamic indices or passive leg raising. However, being a pilot study, we measured these parameters in patients with sinus rhythm under closed chest condition, which merits further studies in a wide variety of patients in different clinical scenarios to prove its predictive ability on fluid responsiveness independent from heart-lung interaction or heart rhythm.

This study is subject to the following limitations. First, we used the lateral mitral annulus for TDI assessment. For simplicity, lateral $\mathrm{E}^{\prime}$ velocity is recommended given the potential influence of the right ventricle on septal $E^{\prime}$ velocity [27]. However, the average of mitral annular velocities measured at different sites would have been the ideal method. Second, although the echocardiographic values were obtained during apnea at atmospheric pressure, anesthesia itself influences loading conditions. Thus, different cut-off values regarding $E$ velocity and to a lesser extent $E^{\prime}$ velocity are likely to be present in awake patients that need to be validated through further studies. Lastly, the difference in the incidence of diabetes and cerebrovascular accident between the responders and nonresponders may have conveyed different influences on the vasculature and thus, diastology, which could not be expected and accounted for in this prospective, observational study.

\section{Conclusions}

In conclusions, the combined index of echocardiographic variables reflecting $\mathrm{LV}$ dimension (LVEDA) and diastolic compliance and filling $\left(\mathrm{E} / \mathrm{E}^{\prime}\right)$ can be a useful predictor of fluid responsiveness in anesthetized patients with preserved LV ejection fraction undergoing surgical coronary revascularization, showing better predictive ability than PPV in this subset of patients.

Author Contributions: Conceptualization, J.-K.S. and H.-B.K.; methodology, J.-K.S., H.-B.K. and S.S.; formal analysis, H.-B.K. and J.-W.S.; investigation, H.-B.K. and M.-Y.K.; resources, H.-B.K. and S.S.; data curation, H.-B.K. and S.S.; writing-original draft preparation, H.-B.K.; writingreview and editing, J.-K.S. and Y.-L.K.; visualization, J.-K.S. and H.-B.K.; supervision, J.-K.S.; project administration, J.-K.S. All authors have read and agreed to the published version of the manuscript.

Funding: Support was provided solely from departmental sources.

Institutional Review Board Statement: The study was conducted according to the guidelines of the Declaration of Helsinki and approved by the Institutional Review Board of Severance Hospital, Yonsei University Health System, Seoul, Korea (IRB no.: 4-2017-0403).

Informed Consent Statement: Informed consent was obtained from all subjects involved in the study.

Data Availability Statement: The data presented in this study are available on request from the corresponding author.

Acknowledgments: We would like to express our great appreciation to Won-Jeong Son and Hye-Jung Shin of the Biostatistics Collaboration Unit, Department of Biomedical Systems Informatics, Yonsei University College of Medicine, for their invaluable support regarding the statistical analyses. We also thank Medical Illustration \& Design, part of the Medical Research Support Services of Yonsei University College of Medicine, for all artistic support related to this work.

Conflicts of Interest: The authors declare no conflict of interest.

\section{References}

1. Marik, P.E.; Baram, M.; Vahid, B. Does central venous pressure predict fluid responsiveness? A systematic review of the literature and the tale of seven mares. Chest 2008, 134, 172-178. [CrossRef]

2. Boyd, J.H.; Forbes, J.; Nakada, T.A.; Walley, K.R.; Russell, J.A. Fluid resuscitation in septic shock: A positive fluid balance and elevated central venous pressure are associated with increased mortality. Crit. Care Med. 2011, 39, 259-265. [CrossRef] 
3. Marik, P.E.; Cavallazzi, R.; Vasu, T.; Hirani, A. Dynamic changes in arterial waveform derived variables and fluid responsiveness in mechanically ventilated patients: A systematic review of the literature. Crit. Care Med. 2009, 37, 2642-2647. [CrossRef] [PubMed]

4. Michard, F. Changes in arterial pressure during mechanical ventilation. Anesthesiology 2005, 103, 419-428. [CrossRef] [PubMed]

5. Wyler von Ballmoos, M.; Takala, J.; Roeck, M.; Porta, F.; Tueller, D.; Ganter, C.C.; Schroder, R.; Bracht, H.; Baenziger, B.; Jakob, S.M. Pulse-pressure variation and hemodynamic response in patients with elevated pulmonary artery pressure: A clinical study. Crit. Care 2010, 14, R111. [CrossRef]

6. Kim, S.Y.; Song, Y.; Shim, J.K.; Kwak, Y.L. Effect of pulse pressure on the predictability of stroke volume variation for fluid responsiveness in patients with coronary disease. J. Crit. Care 2013, 28, 318.e1-318.e7. [CrossRef] [PubMed]

7. Osman, D.; Ridel, C.; Ray, P.; Monnet, X.; Anguel, N.; Richard, C.; Teboul, J.L. Cardiac filling pressures are not appropriate to predict hemodynamic response to volume challenge. Crit. Care Med. 2007, 35, 64-68. [CrossRef]

8. Ommen, S.R.; Nishimura, R.A.; Appleton, C.P.; Miller, F.A.; Oh, J.K.; Redfield, M.M.; Tajik, A.J. Clinical utility of doppler echocardiography and tissue doppler imaging in the estimation of left ventricular filling pressures: A comparative simultaneous doppler-catheterization study. Circulation 2000, 102, 1788-1794. [CrossRef]

9. Zile, M.R.; Brutsaert, D.L. New concepts in diastolic dysfunction and diastolic heart failure: Part I: Diagnosis, prognosis, and measurements of diastolic function. Circulation 2002, 105, 1387-1393. [CrossRef] [PubMed]

10. Mogelvang, R.; Sogaard, P.; Pedersen, S.A.; Olsen, N.T.; Marott, J.L.; Schnohr, P.; Goetze, J.P.; Jensen, J.S. Cardiac dysfunction assessed by echocardiographic tissue doppler imaging is an independent predictor of mortality in the general population. Circulation 2009, 119, 2679-2685. [CrossRef]

11. Jacob, R.; Dierberger, B.; Kissling, G. Functional significance of the frank-starling mechanism under physiological and pathophysiological conditions. Eur. Heart J. 1992, 13, 7-14. [CrossRef]

12. Song, Y.; Kwak, Y.L.; Song, J.W.; Kim, Y.J.; Shim, J.K. Respirophasic carotid artery peak velocity variation as a predictor of fluid responsiveness in mechanically ventilated patients with coronary artery disease. Br. J. Anaesth. 2014, 113, 61-66. [CrossRef] [PubMed]

13. Denault, A.; Canty, D.; Azzam, M.; Amir, A.; Gebhard, C.E. Whole body ultrasound in the operating room and intensive care unit. Korean J. Anesthesiol. 2019, 72, 413-428. [CrossRef]

14. Boyd, J.H.; Sirounis, D.; Maizel, J.; Slama, M. Echocardiography as a guide for fluid management. Crit. Care 2016, $20,274$. [CrossRef] [PubMed]

15. Sander, M.; Schneck, E.; Habicher, M. Management of perioperative volume therapy-monitoring and pitfalls. Korean J. Anesthesiol. 2020, 73, 103-113. [CrossRef]

16. Levine, H.J. Compliance of the left ventricle. Circulation 1972, 46, 423-426. [CrossRef]

17. Nagueh, S.F.; Smiseth, O.A.; Appleton, C.P.; Byrd, B.F., 3rd; Dokainish, H.; Edvardsen, T.; Flachskampf, F.A.; Gillebert, T.C.; Klein, A.L.; Lancellotti, P.; et al. Recommendations for the evaluation of left ventricular diastolic function by echocardiography: An update from the american society of echocardiography and the european association of cardiovascular imaging. J. Am. Soc. Echocardiogr. 2016, 29, 277-314. [CrossRef] [PubMed]

18. Mor-Avi, V.; Lang, R.M.; Badano, L.P.; Belohlavek, M.; Cardim, N.M.; Derumeaux, G.; Galderisi, M.; Marwick, T.; Nagueh, S.F.; Sengupta, P.P.; et al. Current and evolving echocardiographic techniques for the quantitative evaluation of cardiac mechanics: ASE/EAE consensus statement on methodology and indications endorsed by the japanese society of echocardiography. J. Am. Soc. Echocardiogr. 2011, 24, 277-313. [CrossRef]

19. Rivas-Gotz, C.; Manolios, M.; Thohan, V.; Nagueh, S.F. Impact of left ventricular ejection fraction on estimation of left ventricular filling pressures using tissue doppler and flow propagation velocity. Am. J. Cardiol. 2003, 91, 780-784. [CrossRef]

20. Kasner, M.; Westermann, D.; Steendijk, P.; Gaub, R.; Wilkenshoff, U.; Weitmann, K.; Hoffmann, W.; Poller, W.; Schultheiss, H.P.; Pauschinger, M.; et al. Utility of doppler echocardiography and tissue doppler imaging in the estimation of diastolic function in heart failure with normal ejection fraction: A comparative doppler-conductance catheterization study. Circulation 2007, 116, 637-647. [CrossRef]

21. Yip, G.W.; Zhang, Y.; Tan, P.Y.; Wang, M.; Ho, P.Y.; Brodin, L.A.; Sanderson, J.E. Left ventricular long-axis changes in early diastole and systole: Impact of systolic function on diastole. Clin. Sci. 2002, 102, 515-522. [CrossRef]

22. Morris, D.A.; Belyavskiy, E.; Aravind-Kumar, R.; Kropf, M.; Frydas, A.; Braunauer, K.; Marquez, E.; Krisper, M.; Lindhorst, R.; Osmanoglou, E.; et al. Potential usefulness and clinical relevance of adding left atrial strain to left atrial volume index in the detection of left ventricular diastolic dysfunction. JACC Cardiovasc. Imaging 2018, 11, 1405-1415. [CrossRef] [PubMed]

23. De Boeck, B.W.; Cramer, M.J.; Oh, J.K.; van der Aa, R.P.; Jaarsma, W. Spectral pulsed tissue doppler imaging in diastole: A tool to increase our insight in and assessment of diastolic relaxation of the left ventricle. Am. Heart J. 2003, 146, 411-419. [CrossRef]

24. Ohte, N.; Narita, H.; Hashimoto, T.; Akita, S.; Kurokawa, K.; Fujinami, T. Evaluation of left ventricular early diastolic performance by color tissue doppler imaging of the mitral annulus. Am. J. Cardiol. 1998, 82, 1414-1417. [CrossRef]

25. Marques, N.R.; De Riese, J.; Yelverton, B.C.; McQuitty, C.; Jupiter, D.; Willmann, K.; Salter, M.; Kinsky, M.; Johnston, W.E. Diastolic function and peripheral venous pressure as indices for fluid responsiveness in cardiac surgical patients. J. Cardiothorac. Vasc. Anesth. 2019, 33, 2208-2215. [CrossRef] 
26. Shim, J.K.; Song, J.W.; Song, Y.; Kim, J.H.; Kang, H.M.; Kwak, Y.L. Pulse pressure variation is not a valid predictor of fluid responsiveness in patients with elevated left ventricular filling pressure. J. Crit. Care 2014, 29, 987-991. [CrossRef] [PubMed]

27. Mitter, S.S.; Shah, S.J.; Thomas, J.D. A test in context: E/A and E/e' to assess diastolic dysfunction and LV filling pressure. J. Am. Coll. Cardiol. 2017, 69, 1451-1464. [CrossRef] 